\title{
Bronchoscopic Evaluation in Clinically and Radiologically Suspected Lung Carcinoma
}

\author{
Sukanta Kodali ${ }^{1}$, Sumanta Jha르, Subhankar Chakraborty ${ }^{3}$, Jaydip Deb ${ }^{4}$, Amiya Dwari ${ }^{5}$, Abhijit Mandal ${ }^{6}$
}

\begin{abstract}
${ }^{1}$ Department of Pulmonary Medicine, Nilratan Sircar Medical College and Hospital, Kolkata, West Bengal, India. ${ }^{2}$ Department of Pulmonary Medicine, Nilratan Sircar Medical College and Hospital, Kolkata, West Bengal, India. ${ }^{3}$ Department of Pulmonary Medicine, Nilratan Sircar Medical College and Hospital, Kolkata, West Bengal, India. 4Department of Pulmonary Medicine, Nilratan Sircar Medical College and Hospital, Kolkata, West Bengal, India. 5Department of Pulmonary Medicine, Nilratan Sircar Medical College and Hospital, Kolkata, West Bengal, India. ${ }^{6}$ Department of Pulmonary Medicine, Nilratan Sircar Medical College and Hospital, Kolkata, West Bengal, India.
\end{abstract}

\section{ABSTRACT}

\section{BACKGROUND}

Lung cancer is generally diagnosed during late stage of the disease; so, early diagnosis of lung cancer is very important to reduce lung cancer death rate. Flexible fibreoptic bronchoscopy (FOB) is an important diagnostic technique performed in patients with suspected malignant lung lesion as it provides sufficient cytologic and histologic specimens in the form of bronchial washing, bronchial brushing and bronchial forceps biopsy.

\section{METHODS}

The present descriptive study analysed cytology of bronchial washing, bronchial brushing and histology of bronchial biopsy in 100 patients with suspected lung cancer. Patients in whom clinical and radiological findings suggested lung carcinoma, were included in the study. Patients with coagulopathy, refractory hypoxemia, cardiac instability, poor ability to cooperate with the procedure were excluded from this study. Age, gender, smoking habits, clinical and radiological findings, various histological types of malignancies, and yield of various bronchoscopic diagnostic techniques in the diagnosis of lung cancer were evaluated.

\section{RESULTS}

Of the 100 cases, $86(86 \%)$ were males and $14(14 \%)$ were females with male to female ratio of $6.14: 1$. The mean age in this study group was 58 years. Overall diagnostic yield by means of all techniques during bronchoscopy was 90\% (90/100 patients). Squamous cell carcinoma was the most common primary bronchogenic tumour 36.67\% (33/90 patients) followed by Adenocarcinoma 25.56\% (23/90 patients), small cell carcinoma 24.44\% (22/90 patients), Undifferentiated NonSmall Cell Carcinoma (NSCLC) $12.22 \%$ (11/90 patients), poorly differentiated carcinoma 1 patient. No evidence of malignancy was found in 10 patients by all techniques during bronchoscopy.

\section{CONCLUSIONS}

Lung cancer is a common malignancy with male preponderance. Bronchial washing and brushing cytology in combination with bronchial biopsy has a very high diagnostic yield. Therefore, all these techniques may be used concurrently to diagnose lung malignancy.

\section{KEY WORDS}

Fibreoptic Bronchoscopy, Non-Small Cell Carcinoma, Bronchoalveolar Lavage
Corresponding Author:

Dr. Sukanta Kodali,

Andul Chowdhury Para,

P.O. Andul-Mouri,

District-Howrah-711302,

West Bengal, India.

E-mail: sukantakodali@gmail.com

DOI: $10.14260 /$ jemds/2020/360

Financial or Other Competing Interests: None.

How to Cite This Article:

Kodali S, Jha S, Chakraborty $S$, et al. Bronchoscopic evaluation in clinically and radiologically suspected lung carcinoma. J. Evolution Med. Dent. Sci. 2020;9(21): 1641-1645, DOI 10.14260/jemds/2020/360

Submission 16-02-2020 ,

Peer Review 04-05-2020,

Acceptance 11-05-2020,

Published 25-05-2020.

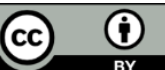




\section{BACKGROUND}

Lung cancer is the most frequently diagnosed cancer and also the leading cause of all cancer associated deaths in the world. ${ }^{1}$ Previously bronchogenic carcinoma was considered to be infrequent in India, but in the recent past a trend of increase in its incidence has been noticed. ${ }^{2}$ In India, lung cancer is the fifth most common cancer. ${ }^{2,3}$ Squamous cell type is the most common cell type in smokers and adenocarcinoma in non-smokers. ${ }^{4}$

Flexible fibreoptic bronchoscopy was developed in the late 1960 s by S. Ikeda and has become the mainstay investigation in the evaluation of patients suspected of lung cancer. ${ }^{5}$ It is employed mainly as a diagnostic tool providing tissue to determine the histological type of tumour. The flexibility of the bronchoscope allows the operator to inspect the majority of fourth order and often up to sixth order bronchi. ${ }^{6}$ The main sampling techniques performed at flexible fibreoptic bronchoscopy include endobronchial forceps biopsy for central tumours and transbronchial forceps biopsy for more peripheral tumours.7,8 Bronchial washing and bronchial brushing specimens can also be obtained for cytopathological examination. ${ }^{9}$ The diagnostic yield of bronchial biopsy specimens varies from 70 to 90 per cent depending on the site and type of the tumour, number of specimens examined, and experience of the pathologist and the bronchoscopist. Central lesions, with visible tumours and multiple samples give a better diagnostic yield. ${ }^{2}$

An attempt was made to evaluate clinically and radiologically suspected lung carcinoma patients by various bronchoscopic techniques. Age, gender, smoking habits, clinical and radiological manifestations, various histological types of malignancy and the yield of various bronchoscopic techniques in the diagnosis of this disease were evaluated.

\section{METHODS}

It was a descriptive study conducted in the Department of Pulmonary Medicine of a tertiary care hospital. The samples for cytological and histological examination were collected from the patients in whom clinical and radiological findings suggested lung carcinoma. A total of 100 cases were included in the study. Flexible fibreoptic bronchoscopy was performed under local anaesthesia along with sedation with intravenous midazolam wherever required. Bronchial washing was obtained by aspiration of any secretion and instillation, followed by immediate aspiration of two aliquots of $20 \mathrm{ml}$ of sterile isotonic $0.9 \%$ saline solution. Samples were centrifuged and prepared into air dried smear. Bronchial brushing was obtained from the surface of endobronchial lesions by the use of a stiff-bristle sheathed disposable brush. Brushing material was smeared directly on to at least three clean glass slides. Bronchial biopsies were performed with alligator forceps with serrated jaws. The specimens were immediately fixed in $10 \%$ buffered formalin.

\section{Inclusion Criteria}

The patients were included in the study were all the patients, admitted in Department of Pulmonary Medicine of our hospital in whom clinical and radiological findings suggested lung carcinoma.

\section{Exclusion Criteria}

Patients with coagulopathy which cannot be corrected, platelets $<50,000$ per microliter, refractory hypoxemia, recent myocardial infarction or unstable angina, major cardiac arrhythmia, hemodynamic instability, and poor ability to cooperate with the procedure were excluded from this study.

\section{RESULTS}

Of the 100 cases, $86 \%$ (86/100 patients) were males and $14 \%(14 / 100$ patients) were females with male to female ratio of 6.14:1. The mean age in this study group was 58 years with a range of 25-82 years (table I). The prevalence of smoking was $79 \%$ (79/100 patients) in the study population. $89.53 \%$ (77/86 patients) male patients and $14.29 \%(2 / 14$ patients) female patients were smoker. Most frequent observed symptoms were cough $(65 \%)$, shortness of breath (35\%), chest pain (32\%), haemoptysis $(27 \%)$, and hoarseness of voice $(5 \%)$. The most common observed general physical sign was clubbing (18\%). Other signs such as lymphadenopathy and superior vena cava syndrome were seen in $15 \%$ and $10 \%$, respectively. Radiological abnormalities documented in study were mass lesion $86 \%$, hilar opacity 47\%, collapse (segmental/lobar) 29\%, and pleural effusion $34 \%$.

All clinically and radiologically suspected patients of lung malignancy underwent fibreoptic bronchoscopy in our bronchoscopy suit. During bronchoscopic procedure, abnormalities were noted as exophytic endobronchial, submucosal, peribronchial lesions. Exophytic endobronchial lesions were seen in 65 cases (65\%), submucosal lesions in 29 cases (29\%) and peribronchial lesions in 06 cases (06\%). Bronchial washing was positive for malignant cells in $61.54 \%$ (40/65 patients) in exophytic endobronchial lesions, 51.72\% $(15 / 29$ patients) in submucosal lesions, $33.33 \% \quad(2 / 6$ patients) in peribronchial lesions. Bronchial brushing had positive diagnostic yield of $80 \%(52 / 65$ patients $)$ in exophytic endobronchial lesions, 58.62\% (17/29 patients) in submucosal lesions, $50 \%$ (3/6 patients) in peribronchial lesions. Bronchial biopsy had positive diagnostic yield of $100 \%$ (65/65 patients) in exophytic endobronchial lesions, $68.97 \%$ (20/29 patients) in submucosal lesions, 66.67\% (4/6 patients) in peribronchial lesions. Bronchial biopsy was most sensitive (89\%) followed by bronchial brushing (72\%) and bronchial washing (57\%) (table II).

In one case, bronchial brushing and biopsy were negative but bronchial washing was positive for malignancy. Overall diagnostic yield by means of all techniques during bronchoscopy was $90 \%$ (90/100 patients). Table III showed evaluation of the role of bronchoscopic techniques in diagnosis of lung cancer. Squamous cell carcinoma was the predominant histopathological pattern 28/65 patients $(43.08 \%)$ in exophytic endobronchial lesions. Small cell carcinoma and Adenocarcinoma were the predominant histopathological pattern $9 / 21$ patients (42.86\%) and $8 / 21$ 
patients (38.10\%) respectively in submucosal lesions. Squamous cell carcinoma was the predominant histopathological pattern $2 / 4$ patients $(50 \%)$ in peribronchial lesions (Table IV).

Overall, Squamous cell carcinoma was the most common primary bronchogenic tumour $36.67 \%$ (33/90 patients) followed by Adenocarcinoma 25.56\% (23/90 patients), small cell carcinoma $24.44 \%$ (22/90 patients), Undifferentiated Non-Small cell carcinoma $12.22 \%$ (11/90 patients), poorly differentiated carcinoma 1 patient (table V). No evidence of malignancy found in 10 patients by all techniques during bronchoscopy.

\begin{tabular}{|ccccc|}
\hline Age Groups (years) & Male & Female & Total & Percentage \\
$<40$ & 1 & 3 & 4 & 4 \\
$40-49$ & 10 & 3 & 13 & 13 \\
$50-59$ & 26 & 3 & 29 & 29 \\
$60-69$ & 36 & 5 & 41 & 41 \\
$70-79$ & 11 & 0 & 11 & 11 \\
$\geq 80$ & 2 & 0 & 2 & 2 \\
Total & $\mathbf{8 6}$ & $\mathbf{1 4}$ & $\mathbf{1 0 0}$ & $\mathbf{1 0 0}$ \\
\hline \multicolumn{5}{c}{ Table I. Age and Sex Distribution } \\
\hline
\end{tabular}

\begin{tabular}{|c|c|c|c|c|c|c|c|c|c|c|}
\hline \multirow[b]{2}{*}{ Technique } & \multicolumn{3}{|c|}{$\begin{array}{l}\text { Endobronchial } \\
\text { Exophytic Growth }\end{array}$} & \multicolumn{3}{|c|}{$\begin{array}{l}\text { Submucosal } \\
\text { Lesions }\end{array}$} & \multicolumn{3}{|c|}{$\begin{array}{l}\text { Peribronchial } \\
\text { Lesions }\end{array}$} & \multirow{2}{*}{$\begin{array}{l}\frac{0}{d} \\
\frac{3}{3} \\
\frac{3}{0} \\
0 \\
0\end{array}$} \\
\hline & 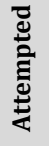 & 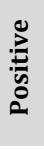 & 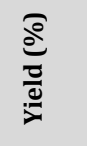 & 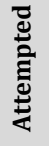 & 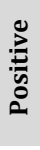 & 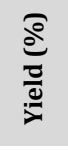 & 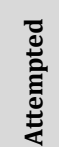 & 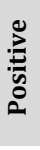 & 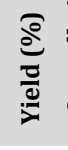 & \\
\hline $\begin{array}{l}\text { Bronchial } \\
\text { washing }\end{array}$ & 65 & 40 & 61.54 & 29 & 15 & 51.72 & 6 & 2 & 33.33 & 57 \\
\hline $\begin{array}{l}\text { Bronchial } \\
\text { brushing }\end{array}$ & 65 & 52 & 80 & 29 & 17 & 58.62 & 6 & 3 & 50 & 72 \\
\hline $\begin{array}{l}\text { Bronchial } \\
\text { biopsies }\end{array}$ & 65 & 65 & 100 & 29 & 20 & 68.97 & 6 & 4 & 66.67 & 89 \\
\hline
\end{tabular}

\begin{tabular}{|ccc|}
\hline $\begin{array}{c}\text { Bronchial Washing, } \\
\text { Brushing and Biopsy Positivity }\end{array}$ & $\begin{array}{c}\text { Total No. of Cases. } \\
\text { (n=100) }\end{array}$ & $\mathbf{\%}$ \\
$\begin{array}{c}\text { Negative by all three techniques } \\
\text { Positive by all three techniques }\end{array}$ & 10 & 10 \\
Positive by biopsy but negative by washing and \\
$\begin{array}{c}\text { brushing } \\
\text { Positive by brushing but negative by washing and } \\
\text { biopsy }\end{array}$ & 90 & 90 \\
$\begin{array}{c}\text { Positive by washing but negative by brushing and } \\
\text { biopsy }\end{array}$ & 17 & 17 \\
$\begin{array}{c}\text { Biopsy and brushing positive but washing negative } \\
\text { Biopsy and washing positive but brushing negative }\end{array}$ & 1 & 0 \\
Washing and brushing positive but biopsy negative & 15 & 1 \\
\hline Table III. Evaluation of the Role of Bronchoscopic \\
Techniques in Diagnosis of Lung Cancer
\end{tabular}

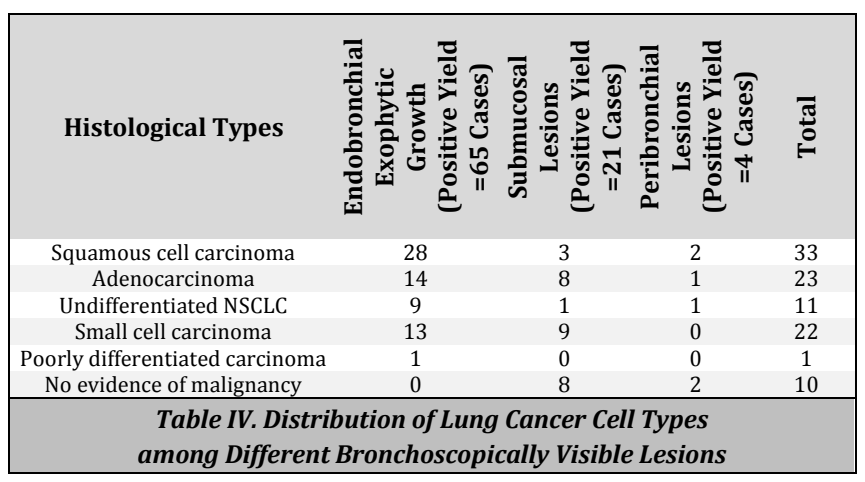

\begin{tabular}{|ccccc|}
\hline Histological Types & Male & Female & Total (n=90) & $\mathbf{\%}$ \\
Squamous cell carcinoma & 33 & 0 & 33 & 33.67 \\
Adenocarcinoma & 12 & 11 & 23 & 25.56 \\
Undifferentiated NSCLC & 10 & 1 & 11 & 12.22 \\
Small cell carcinoma & 21 & 1 & 22 & 24.44 \\
Poorly differentiated carcinoma & 1 & 0 & 1 & 1.11 \\
\hline \multicolumn{4}{r|}{ Table V. Histopathological Diagnosis by Means } \\
of All Techniques during Bronchoscopy \\
\hline
\end{tabular}

\section{DISCUSSION}

In current study majority of the patients diagnosed to have bronchogenic carcinoma were in their sixth and seventh decades of life (50-70 years). The mean age in study group was 58 years. These observations are consistent with many Indian studies done in the past in which the mean age was between fifty and seventy years. ${ }^{2,3}$ The disease is known to be more common in males than in females. In current study, 86 $(86 \%)$ were males and $14(14 \%)$ were females with male to female ratio of 6.14:1. In another study of 638 patients diagnosed to have lung cancers, males and females were in a ratio of 6.7:1.10 Other authors have also reported similar ratio in the previous studies. ${ }^{2}$

Tobacco smoking along with rising levels of environmental pollution has been implicated in causation of lung cancer. In the present study, $79 \%$ of the patients were smokers, once again suggesting a close link between this habit and the development of the disease. 89.53\% (77/86 patients) male patients and $14.29 \%$ (2/14 patients) female patients were smoker in our study. In a study by Gupta et al, $80 \%$ of men and $33 \%$ of women among the patients were ever-smokers as compared to $60 \%$ of men and $20 \%$ of women among controls. ${ }^{11}$ In the present study, smoking has been the predominant contributory factor both in males and females. Due to the same reason, squamous cell carcinoma was the commonest malignancy (36.67\%) detected in present study.

Most frequent observed symptoms were cough (65\%), shortness of breath (35\%), chest pain (32\%), haemoptysis $(27 \%)$, and hoarseness of voice $(5 \%)$. The most common observed general physical sign was clubbing (18\%). Other signs such as lymphadenopathy and superior vena cava syndrome were seen in $15 \%$ and $10 \%$, respectively. Shital Patil et al reported similar types of observations. ${ }^{12}$ Radiological abnormalities documented in study were mass lesion $86 \%$, hilar opacity $47 \%$, collapse (segmental/lobar) $29 \%$, and pleural effusion $34 \%$. Sharma CP et al reported mass with or without collapse is the commonest radiological finding in lung cancer. ${ }^{13}$ All clinically and radiologically suspected patients of lung malignancy underwent fibreoptic bronchoscopy in our Bronchoscopy suit.

During bronchoscopic procedure, abnormalities were noted as exophytic endobronchial, submucosal, peribronchial lesions. Exophytic endobronchial lesions predominant bronchoscopic findings were cauliflower, polypoidal-like or nodular or multinodular endobronchial growth. Submucosal lesions predominant bronchoscopic findings were erythema, vascular flares and enhanced rugal pattern, loss of normal bronchial markings, or thickening of mucosa and narrowing of bronchus. Peribronchial lesions predominant bronchoscopic findings are narrowing of airway due to extrinsic compression of airways by tumour or lymphadenopathy, or bulge seen in the lumen. Exophytic endobronchial lesions were seen in 65 cases (65\%), submucosal lesions in 29 cases (29\%) and peribronchial lesions in 06 cases (06\%).

Bronchial washing was positive for malignant cells in $61.54 \%$ (40/65 patients) in exophytic endobronchial lesions, $51.72 \%$ (15/29 patients) in submucosal lesions, 33.33\% (2/6 patients) in peribronchial lesions. However, the sensitivity of 
BAL (bronchoalveolar lavage) in various other studies from literature varies widely from $21 \%$ to $78 \% .14,15$ This wide range of sensitivity may be due to difference in case selection. The adequacy of BAL samples depends on several crucial factors such as the degree of differentiation of malignant growth, preservation of the morphology of cytological material obtained and technical skill of the pulmonologist. Rennard SI suggested that yield can be improved by taking multiple samples.

Bronchial brushing had positive diagnostic yield of $80 \%$ (52/65 patients) in exophytic endobronchial lesions, 58.62\% (17/29 patients) in submucosal lesions, 50\% (3/6 patients) in peribronchial lesions. Chopra et al have reported the sensitivity of bronchial brushing to be as high as $86.3 \%$ in their study. ${ }^{16}$ Bronchial biopsy had positive diagnostic yield of $100 \%$ (65/65 patients) in exophytic endobronchial lesions, $68.97 \%$ (20/29 patients) in submucosal lesions, 66.67\% (4/6 patients) in peribronchial lesions. Bhat $\mathrm{N}$ evaluated 902 bronchial biopsy specimens in suspected cases of lung cancer and found that $760(84.25 \%)$ cases were diagnosed by bronchial biopsy to be suffering from lung cancer, of which 647 were males and 113 were females. ${ }^{17}$ Bronchial biopsy was most sensitive (89\%) followed by bronchial brushing (72\%) and bronchial washing (57\%).

Overall diagnostic yield by means of all techniques during bronchoscopy was 90\% (90/100 patients) in our study. Rivera MP, Mehta AC et al produced Data from 4507 patients revealed that central endobronchial biopsies provide the highest sensitivity (74\%), followed by brushing (61\%) and washing $(47 \%)$. The combination provides a diagnosis in $88 \%$ of cases. ${ }^{18}$ Bronchial biopsy was most sensitive (89\%) followed by bronchial brushing (72\%) and bronchial washing (57\%). In one case, brushing and biopsy were negative but bronchial washing was positive for malignancy. This is possible when sometimes the biopsy is taken from the necrotic part of the tumour.

Squamous cell carcinoma was the predominant histopathological pattern $28 / 65$ patients (43.08\%) in exophytic endobronchial lesions. Small cell carcinoma and Adenocarcinoma were the predominant histopathological pattern $9 / 21$ patients $(42.86 \%)$ and $8 / 21$ patients $(38.10 \%)$ respectively in submucosal lesions. Squamous cell carcinoma was the predominant histopathological pattern $2 / 4$ patients $(50 \%)$ in peribronchial lesions.

Overall, Squamous cell carcinoma was the most common primary bronchogenic tumour $36.67 \%$ (33/90 patients) followed by Adenocarcinoma 25.56\% (23/90 patients), small cell carcinoma $24.44 \%$ (22/90 patients), Undifferentiated Non-Small cell carcinoma $12.22 \%$ (11/90 patients), poorly differentiated carcinoma 1 patient. No evidence of malignancy found in 10 patients by all techniques during bronchoscopy. Most of the studies in India suggest a higher prevalence of Squamous cell carcinoma. Gupta et al, detected 42.3\% squamous cell carcinoma and $19.9 \%$ adenocarcinoma in their study. ${ }^{19}$ Similarly, Thippanna et al, in their study done in 1998 found $67.5 \%$ patients of squamous cell carcinoma in contrast to $18.75 \%$ adenocarcinoma patients. ${ }^{20}$ Kashyap et al, also found $58.3 \%$ squamous cell and $10.8 \%$ adenocarcinoma patients in their study group. ${ }^{10}$ The yield of diagnosis was highest with bronchoscopic biopsies and in maximum number of cases, specific histological diagnosis was made by biopsies alone. The number of biopsies taken has been shown to affect the positive yield rate; one study reporting that 5 biopsies were needed to achieve a greater than $90 \%$ probability of obtaining at least one positive sample in cases of carcinoma. ${ }^{21}$ but it is best to combine all the diagnostic modalities like biopsies, brushing and lavage in any patient.

One of the limitations of our study was use of only bronchial biopsy for the validation of cytological techniques and the absence of other confirmatory tests like surgical biopsy, transbronchial needle aspiration, transthoracic needle aspiration, mediastinoscopy, biopsies of extrapulmonary lesions and autopsy. Other limitation was the inability to further sub-typing of poorly differentiated nonsmall cell carcinomas in the absence of immunohistochemistry.

\section{CONCLUSIONS}

The present study emphasizes the fact that lung cancer is common among male smokers with squamous cell carcinoma as the most common histological type. Bronchial washing and brushing cytology in combination with bronchial biopsy has a very high diagnostic yield. Therefore, all these techniques may be used concurrently to diagnose lung malignancy.

\section{REFERENCES}

[1] Parkin DM, Bray F, Ferlay J, et al. Global cancer statistics, 2002. CA Cancer J Clin 2005;55 (2):74-108.

[2] Behera D, Balamugesh T. Lung cancer in India. Indian J Chest Dis Allied Sci 2004;46 (4):269-81.

[3] Agarwal A, Ghotekar LH, Garbyal RS, et al. Evaluation of pulmonary malignancies in Kathmandu valley and role of bronchoscopic techniques in diagnosis of such cases. J Indian Academy Clin Med 2003;4 (2):127-33.

[4] Kumar V, Gupta KB, Aggarwal R. Yield of different bronchoscopic techniques in diagnosis of lung cancer. International Journal of Research in Medical Sciences 2017;5 (9):4098-103.

[5] Ohata M. History and progress of bronchology in Japan. Japan Society for Brochology 1998;20:539-46.

[6] Barle'si F, Doddoli C, Greillier L, et al. Bronchoscopy in the diagnosis of lung cancer: an evaluation of current practice. Rev Mal Respir 2006;23 (Suppl 2):17-26.

[7] Zavala DC. Diagnostic fiberoptic bronchoscopy: techniques and results of biopsy in 600 patients. Chest 1975;68 (1):12-9.

[8] Schreiber G, McCrory DC. Performance characteristics of different modalities for diagnosis of suspected lung cancer: summary of published evidence. Chest 2003;123 (Suppl 1):S115-28.

[9] Rennard SI. Bronchoalveolar lavage in the diagnosis of cancer. Lung 1990; (Suppl 168):1035-40.

[10] Kashyap S, Mohapatra PR, Negi RS. Pattern of primary lung cancer among bidi smokers in North-Western Himalayan region of India. Lung Cancer 2003;41 (Suppl 2):S111. 
[11] Gupta D, Boffetta P, Gaborieau V, et al. Risk factors of lung cancer in Chandigarh, India. Indian J Med Res 2001;113:142-50.

[12] Patil S, Rujuta A. Bronchoscopic characterization of lesions: significant impact on lung cancer diagnosis with use of Transbronchial Needle Aspiration (TBNA) in comparison to conventional diagnostic techniques (CDTs). Clinical Cancer Investigation Journal 2017;6 (6):239-46.

[13] Sharma CP, Behera D, Aggarwal AN, et al. Radiographic patterns in lung cancer. Indian J Chest Dis Allied Sci 2002;44 (1):25-30.

[14] Garg S, Handa U, Mohan H, et al. Comparative analysis of various cyto-histological techniques in diagnosis of lung diseases. Diagn Cytopathol 2007;35 (1):26-31.

[15] Truong LD, Underwood RD, Greenberg SD, et al. Diagnosis and typing of lung carcinomas by cytopathologic methods. A review of 108 cases. Acta Cytol 1985;29 (3):379-84.

[16] Chopra SK, Genovesi MG, Simmons DH, et al. Fiberoptic bronchoscopy in the diagnosis of lung cancer comparison of pre-and post-bronchoscopy sputa, washing, brushing and biopsies. Acta Cytol 1977;21(4):524-7.
[17] Bhat N, Nazeir MJ, Bashir $H$, et al. Correlation of bronchial biopsy with bronchoalveolar lavage in lung malignancies. Int J Res Med Sci 2016;4 (2):428-35.

[18] Rivera MP, Mehta AC, American College of Chest Physicians. Initial diagnosis of lung cancer: ACCP evidence-based clinical practice guidelines (2nd edition). Chest 2007;132 (Suppl 3):131S-48S.

[19] Gupta RC, Purohit SD, Sharma MP, et al. Primary bronchogenic carcinoma: clinical profile of 279 cases from mid-west Rajasthan. Indian J Chest Dis Allied Sci 1998;40 (2):109-16.

[20] Thippanna G, Venu K, Gopalkrishnaiah V, et al. A profile of lung cancer patients in Hyderabad. J Indian Med Assoc 1999;97 (9):357-9.

[21] Gellert AR, Rudd RM, Sinha G, et al. Fibreoptic bronchoscopy: effect of multiple bronchial biopsies on diagnostic yield in bronchial carcinoma. Thorax 1982;37 (9):684-7. 